\title{
Marketing depression care management to employers: design of a randomized controlled trial
}

\author{
Kathryn M Rost ${ }^{1 *}$, Donna Marshall ${ }^{2}$
}

\begin{abstract}
Background: Randomized trials demonstrate that depression care management can improve clinical and work outcomes sufficiently for selected employers to realize a return on investment. Employers can now purchase depression products that provide depression care management, defined as employee screening, education, monitoring, and clinician feedback for all depressed employees. We developed an intervention to encourage employers to purchase a depression product that offers the type, intensity, and duration of care management shown to improve clinical and work outcomes.
\end{abstract}

Methods: In a randomized controlled trial conducted with 360 employers of 30 regional business coalitions, the research team proposes to compare the impact of a value-based marketing intervention to usual-care marketing on employer purchase of depression products. The study will also identify mediators and organizational-level moderators of intervention impact. Employers randomized to the value-based condition receive a presentation encouraging them to purchase depression products scientifically shown to benefit the employee and the employer. Employers randomized to the usual-care condition receive a presentation encouraging them to monitor and improve quality indicators for outpatient depression treatment. Because previous research demonstrates that the usual-care intervention will have little to no impact on employer purchasing, depression product purchasing rates in the usual-care condition capture vendor efforts to market depression products to employers in both conditions while the value-based intervention is being conducted. Employers in both conditions are also provided free technical assistance to undertake the actions each presentation encourages. The research team will use intentto-treat models of all available data to evaluate intervention impact on the purchase of depression products using a cumulative incidence analysis of 12- and 24-month data.

Discussion: By addressing the 'value to whom?' question, the study advances knowledge about one of the most pivotal problems in the translation of evidence-based care to 'real world' settings: whether purchasers can be influenced to buy healthcare products on the basis of value and not exclusively on the basis of cost. If value-based marketing increases depression product purchase rates over usual care, this study will provide encouragement to market new healthcare products on the basis of the product's value to the purchaser as well as the recipient of care.

Trial Registration: Clinical Trials Registration Number: NCT01013220

\footnotetext{
* Correspondence: kathryn.rost@med.fsu.edu

'Department of Medical Humanities and Social Sciences, Florida State

University College of Medicine, Tallahassee, Florida, USA
} 


\section{Background}

Recent studies estimate that $7.6 \%$ of employees suffer a major depressive episode each year [1]. Depression substantially reduces an employee's ability to work, as evidenced by increased absenteeism [2-5] and reduced productivity at work (hereafter referred to as productivity) [2-7], with annual work costs approaching $\$ 24$ billion (Y2K\$) [1]. As the most prevalent disorder of the five conditions that cause the greatest work loss in the American workforce $[8,9]$, depression will soon become the leading cause of disability in industrialized countries [10].

Employers can reduce their depression-related work losses by ensuring their employees receive the type, intensity and duration of depression care management shown to improve clinical and work outcomes in effectiveness trials [11-14]. Employers, who finance health insurance coverage for an estimated $90 \%$ of non-elderly individuals with private health insurance [15], can purchase products that increase the probability that their depressed employees receive this evidence-based care. Interventions to increase product purchase need to increase employer motivation and capacity to purchase.

\section{Increasing employer motivation to purchase}

In the studies to date, employers report substantial information deficits about the costs that organizations absorb when depressed employees fail to receive adequate treatment. Employers who receive this information report interest in reviewing the data that depression products achieve a return on investment. Even more encouragingly, employers note that they are willing to apply program savings from improved absenteeism and productivity against program costs [16-24].

\section{Increasing employer capacity to purchase}

Employers interested in purchasing a depression product that provides value face non-trivial challenges. Employers who contract with multiple health plans have to contract with an additional vendor (e.g., a disease management company or managed behavioral health organization) to provide a depression product to their workforce. Because the marketplace does not currently provide a list of vendors who sell depression products, interested employers often know only those products recommended by their colleagues. Not surprisingly, products differ substantially in their cost and capacity to deliver evidence-based services, requiring employers to make informed choices despite imperfect information to realize value for themselves or their employees. To address this need, this study provides technical assistance to employers to identify high-quality depression products, referring to products that provide the type, intensity, and duration of depression care management shown to improve clinical and work outcomes as Depression Management in the Workplace (DMW) products.

\section{Scope of Study}

The specific aims of the study are: to compare the impact of value-based (VB) and usual-care (UC) intervention on employer purchase of depression products; to identify mediators of intervention impact on employer purchase; and to identify organizational-level moderators of employer purchase.

The first specific aim utilizes an experimental design to study intervention effectiveness. Hypothesis one tests whether VB intervention significantly increases purchasing behavior over UC. The second specific aim utilizes a non-experimental design to study intervention mediators. Hypothesis two tests whether intervention impact on purchasing behavior is mediated by the organization's appraisal of product benefit to the employer more than the employee. Hypothesis three tests whether colleagues influence an organization's appraisal of product benefit to employer. The third specific aim utilizes a non-experimental design to study intervention moderators. Hypothesis four tests whether larger and more mature companies with greater financial latitude demonstrate higher levels of purchasing behavior, as well as companies who make greater investments in their employees and have a higher tolerance for benefit risk, independent of intervention. Hypothesis five tests whether companies with de-centralized onsite purchasing groups in which the presentation participant has primary influence will demonstrate higher levels of purchasing behavior, independent of intervention. Hypothesis six tests whether companies with strong vendor relationships demonstrate higher levels of purchasing behavior, independent of intervention.

Before initiating the study, the research team: fully articulated a conceptual framework; pilot tested the VB intervention prototype to demonstrate intervention feasibility, to collect/integrate employer feedback to further strengthen the intervention, and to estimate effect size; created instrumentation to measure intervention mediators, moderators, and outcomes with demonstrated reliability and validity; investigated business coalition interest in participating in the study; and received approval from the Florida State University Institutional Review Board.

\section{Methods/design \\ Participants and setting \\ Regional Coalitions}

Employers join coalitions in their geographic area to identify innovative solutions to provide quality 
healthcare at affordable prices, focusing on benefit products for their non-unionized employees. The 58 coalition members of the National Business Coalition on Health $(\mathrm{NBCH})$ are eligible to participate in the study if: they have 30 or more current employer purchasers as members/affiliates; have hosted presentations in regularly scheduled meetings during the past year (eliminating a limited number of coalitions who served exclusively as purchasing agents); and have not participated in the research team's preliminary studies. The research team, in conjunction with the $\mathrm{NBCH}$ Board of Directors, sends eligible coalitions an invitation to participate, followed up by a telephone call, describing the purpose of the study as testing two educational presentations on assuring high quality depression care.

\section{Employers}

Employers who belong to regional coalitions are eligible to participate if: they represent a public or private company that provides health benefits to 100 or more domestic employees; their company intends to remain in the regional coalition for the next two years; and the coalition's Executive Director does not indicate they have purchased depression products for all their employees in the past two years. Employers who join regional coalitions appoint one employee from their company to represent them. Unpublished studies indicate that more than $60 \%$ of these representatives report strong influence in benefit purchasing decisions. The Executive Director of each participating coalition distributes a fact sheet to all eligible representatives inviting them to participate in a study that tests two educational presentations about how companies can improve the depression treatment their employees receive. The Executive Director follows up with each member by telephone to confirm that 6 or more employers agree to participate in the study without knowing which condition they will be assigned to.

\section{Randomization}

Participating coalitions are randomized to one of six quarters ending March 2011 for presentation to reduce historical threats to validity in non-experimental analyses. As shown in Figure 1, participating employers within a coalition are block randomized by workforce size to the VB or UC condition. After being alphabetized, all participating employers are assigned a unique two-digit number from a random numbers table created by the principal investigator at a centralized location blinded to all company names. Each participating employer is matched to another participating employer in the same coalition by workforce size before the employer with the higher number in each pair is randomized to the VB condition with the other member randomized to the UC condition. When randomization is completed in each coalition, a member of the research team works with the Executive Director to invite participating employers to the presentation to which they had been randomized. Participants remain blind to intervention condition until the presentation begins.

\section{Intervention}

The intervention consists of a presentation and technical assistance delivered to employer representatives at local meetings sponsored by regional coalitions. Employers randomized to the VB condition receive the Depression Management in the Workplace (DMW) presentation. Employers randomized to the UC condition receive the Healthcare Effectiveness Data and Information Set (HEDIS) presentation. All interested employer representatives are offered condition-specific technical assistance free of charge during the 24 months after the presentation.

\section{Presentations}

The DMW and HEDIS presentations present the content summarized in Table 1 utilizing high quality graphic material recently awarded The Communicators Award of Excellence in an international competition.

\section{DMW presentation}

The two-hour DMW presentation educates employer representatives about DMW Care and its evidencebased impact on clinical and work outcomes. Employer representatives receive a company-specific return on investment (ROI) estimate associated with DMW Care. As shown in Table 2, this estimate is generated by a

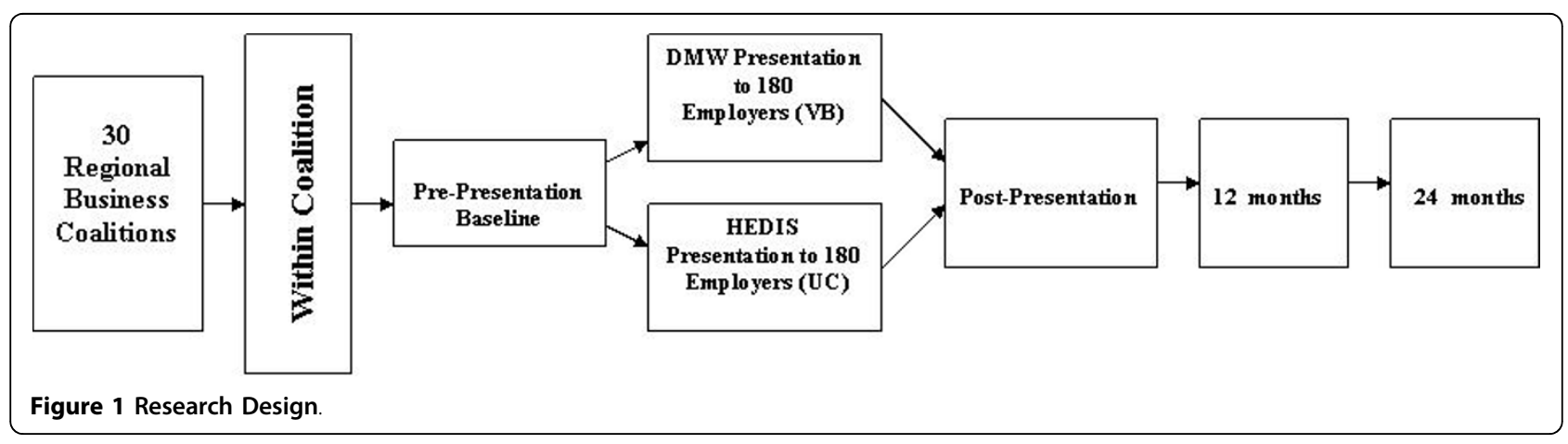


Table 1 Presentation Schematic

\begin{tabular}{lll}
\hline Sequence of Initial Activities & \multicolumn{1}{c}{ VB Presentation } & \multicolumn{1}{c}{ UC Presentation } \\
\hline PRESENTATION & Prevalence in the workplace & Prevalence in society \\
\hline & $\begin{array}{l}\text { Depression burden to } \\
\text { Employer } \\
\text { Employee }\end{array}$ & Depression burden to individual \\
\hline & Problems treating depression in usual care & Problems treating depression in usual care \\
\hline DMW as an indicator of high quality care & HEDIS as an indicator of high quality care \\
\hline Clinical effectiveness of DMW Care & Obtaining HEDIS indicators for outpatient depression management \\
\hline Organizational effectiveness of DMW & \\
\hline DMW Calculator & Interpreting HEDIS indicators for outpatient depression management \\
\hline & Description of Technical Assistance & Description of Technical Assistance \\
\hline & Open discussion of value of DMW Care & Open discussion of value of HEDIS quality care
\end{tabular}

Table 2 Calculator Schematic

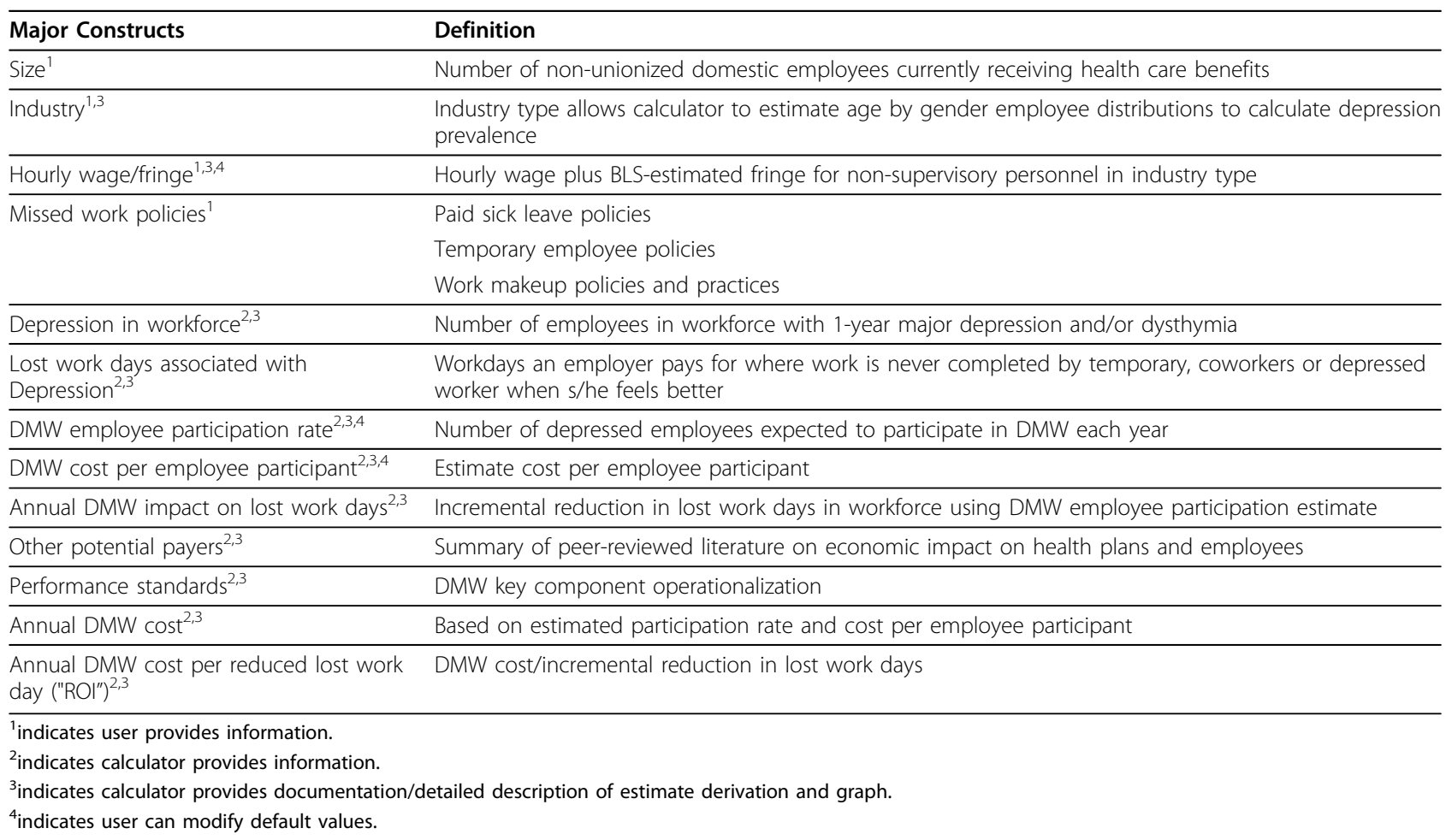

calculator the research team developed in its earlier studies by translating scientifically derived estimates of DMW Care's impact on absenteeism and productivity at work to a monetized savings in lost work days, varying pertinent employee, organizational, and vendor characteristics [25]. During the presentation, employers are encouraged to explore purchasing a depression product for their company and to request free technical assistance to help them purchase a DMW Care quality product.

\section{HEDIS presentation}

The two-hour HEDIS presentation educates employers about HEDIS indicators for antidepressant medication management and their use in monitoring outpatient depression treatment quality. Employers receive HEDIS indicators for antidepressant medication management for their most subscribed plan if that plan reports its HEDIS scores to the National Committee for Quality Assurance; otherwise, they receive the HEDIS indicators for other plans in the area. During the presentation, employers are asked to encourage their most subscribed health plan to improve its HEDIS indicators for depression (or to calculate its HEDIS indicators if it does not report them). In addition, employers are encouraged to ask their plans to provide individual feedback to clinicians about the quality of their depression care, provide 
greater formulary access to newer depression drugs, and require lower copayments for outpatient mental healthcare. While causal evidence is lacking, a study reports that these plan characteristics are associated with better HEDIS indicators for antidepressant medication management [26]. Because previous studies indicate that the HEDIS presentation will have little to no impact on employer purchasing [27-31], depression product purchasing rates in the UC condition capture vendor efforts to market depression products to employers in both conditions during follow-up.

The second author (DM) provides presentations to both groups. DMW and HEDIS presentation sessions are scheduled for the same day in random order, one in the morning and the other in the afternoon. If after agreeing to be in the study, employer representatives fail to attend the meeting, they are asked to schedule a time in the next four weeks to complete the presentation and data collection individually. If they cannot do so, they are dropped from the study.

\section{Technical assistance (TA)}

TA is the provision of individualized consultation to enable employers to improve the depression care their employees receive. When an employer representative requests TA, the TA consultant schedules a two-hour phone call to conduct the initial consultation followed by a second call approximately one month later. In the VB condition, the TA assists employer representatives in building broad support within their organization for the purchase, in identifying DMW vendors, and in developing contracts for the program. In the UC condition, the TA consultant assists employer representatives to work with their most subscribed health plan to improve the depression treatment they deliver as measured by their outpatient antidepressant management HEDIS indicators, and/or to provide individual feedback to clinicians about the quality of their depression care, provide greater formulary access to newer depression drugs, and require lower copayments for outpatient mental healthcare.

\section{Data collection}

All employer representatives are asked to complete the pre-presentation survey immediately before the presentation begins, the post-presentation survey immediately after the presentation ends, as well as a 12- and 24month follow-up survey. Twenty-four-month follow-up surveys are projected to be completed by September 2013. Employers are paid $\$ 100$ for completing the preand post-presentation survey, $\$ 100$ for completing the 12 -month survey, $\$ 100$ for completing the 24-month survey, and an additional $\$ 50$ for completing all surveys. Pre- and post-presentation data are collected in the room in which the presentations are delivered using laptop computers. Twelve- and 24-month follow-up data are collected in the subject's office or home using the web. The research team member who actively contacts employers who do not respond to a standardized electronic cue to complete follow-ups is blinded to condition. Pre-presentation data (descriptive characteristics, mediating, moderating, and outcome variables) are collected from employer representatives immediately before the presentation. Post-presentation data (mediating variables and presentation evaluation) are collected from employer representatives immediately after the presentation. Twelve and 24-month data (mediating, selected moderating and outcome variables) are collected in a three month window of the expected timeframe. Employers whose representatives are no longer in the position or with the company are asked to nominate another representative to complete the presentation and remaining follow-up interviews.

The research team also conducts semi-structured interviews with Executive Directors of each participating coalition at baseline (two weeks before the presentation) and at 24-month follow-up. Executive Director baseline interviews provide qualitative data about coalition efforts to encourage VB purchasing. Executive Director followup interviews are designed to provide qualitative data on intervention impacts that may not be observable in the structured interviews we conducted with employers, as well as solicit insights from Executive Directors about VB intervention impact and strengthening. Instrumentation is available on the project's website [32].

\section{Construct Measurement}

Employer benefit purchasing behavior (EBPB) over the previous 12 months will be measured at 12 and 24 months as an ordinal variable with four levels: product exposure (e.g., presentation participation) only; product exposure and discussion with decision-maker only; product exposure, discussion with decision-maker and product pursuit; and product exposure, discussion with decision making, product pursuit, and product purchase. Planned secondary analyses will examine intervention impact on product purchase defined as a dichotomous variable. Descriptive, moderating, and mediating variables will be defined in subsequent manuscripts testing the study's hypotheses.

\section{Data Analysis}

The research team will test the experimental hypothesis using an intent-to-treat model of all available data, conducting a cumulative incidence analysis over 24 months. Assuming 20\% dropout at 24 months (remaining $\mathrm{n}=$ 144/group), the post-attrition sample will provide $86 \%$ power to find a 0.35 effect size on the EBPB scale using a two-tailed test with $\mathrm{p}<0.05$.

\section{Discussion}

Depression products have potential to reduce the toll depression exacts on employers by increasing the 
delivery of evidence-based care. This trial will determine if an intervention that emphasizes value to the healthcare purchaser as well as to the healthcare recipient can increase product purchase. By addressing the 'value to whom?' question, the study advances knowledge about one of the most pivotal problems in the translation of evidence-based care to 'real world' settings: whether purchasers can be influenced to buy healthcare products on the basis of value rather than only on the basis of cost. In the likely event that VB > UC, the study will provide encouragement to market evidence-based healthcare to purchasers on the basis of the value the organization itself will realize. UC may achieve comparable outcomes to VB if the limiting factors in benefit purchasing are organizational, purchasing group and vendor constraints that no intervention can meaningfully modify. Support for this scenario would encourage the targeted marketing of evidence-based healthcare to purchasers with empirically identified organizational, purchasing group, and vendor characteristics, using usual care strategies.

\section{Acknowledgements}

The authors wish to acknowledge Kristen Berg, Marilyn Jordan, and Benjamin Shearer, all of whom received support from the National Institute of Mental Health MH76277 who funded this investigation.

\section{Author details}

'Department of Medical Humanities and Social Sciences, Florida State University College of Medicine, Tallahassee, Florida, USA. ${ }^{2}$ Colorado Business Group on Health, Denver, Colorado, USA

\section{Authors' contributions}

KR conceived of and designed the study, developed the instrumentation, and drafted the manuscript with assistance from the technical writer. DM made substantial contributions to the study questions to increase the interest of the study to employers; made suggestions to increase the feasibility of intervention implementation and data collection; supervises data collection, and revised the intellectual content of the manuscript. Both KR and DM have read and given final approval of the version to be published, and participated sufficiently in the work to take public responsibility for the content.

\section{Competing interests}

The authors declare that they have no competing financial or non-financial interests. KR developed, directed, and published the intervention study used in part to define DMW Care.

Received: 15 January 2010 Accepted: 16 March 2010

Published: 16 March 2010

\section{References}

1. Birnbaum HG, Kessler RC, Kelley D, Ben-Hamadi R: Employer burden of mild, moderate and severe major depressive disorder: mental health services utilization and costs, and work performance. Depression and Anxiety 2009, 27:78-89.

2. Stewart WF, Ricci JA, Chee E, Hahn SR, Morganstein D: Cost of lost productive work time among US workers with depression. JAMA 2003, 289:3135-3144.

3. Kessler RC, Akiskal HS, Ames M, Birnbaum H, Greenberg P, Hirschfeld RM, Jin R, Merikangas KR, Simon GE, Wang PS: Prevalence and effects of mood disorders on work performance in a nationally representative sample of U.S. workers. Am J Psychiatry 2006, 63:1561-8.
4. Gilmour H, Patten SB: Depression and work impairment. Health Rep 2007 18:9-22.

5. Burton WN, Conti DJ, Chen CY, Schultz AB, Edington DW: The role of health risk factors and disease on worker productivity. J Occup Environ Med 1999, 41:863-877.

6. Wang PS, Beck AL, Berglund P, McKenas DK, Pronk NP, Simon GE, Kessler RC: Effects of major depression on moment-in-time work performance. Am J Psychiatry 2004, 161:1885-91.

7. Martin JK, Blum TC, Beach SR, Roman PM: Subclinical depression and performance at work. Soc Psychiatry Psychiatr Epidemiol 1999, 31:3-9.

8. Kessler RC, Mickelson KD, Barber C, Wang P: The Effects of Chronic Medical Conditions on Work Impairment Chicago: University of Chicago Press 1999.

9. Kessler RC, Greenberg PE, Mickelson KD, Meneades LM, Wang PS: The effects of chronic medical conditions on work loss and work cutback J Occup Environ Med 2001, 43:218-25.

10. Murray C, Lopez A: The Global Burden of Disease: A Comprehensive Assessment of Mortality and Disability from Diseases, Injuries, and Risk Factors in 1990 and Projected to 2020 Boston: The Harvard School of Public Health on Behalf of the World Health Organization and the World Bank 1996

11. Rost $K$, Smith $J$, Dickinson M: The effect of improving primary care depression management on employee absenteeism and productivity: a randomized trial. Med Care 2004, 42:1202-1210.

12. Wang PS, Simon GE, Avorn J, Azocar F, Ludman EJ, McCulloch J, Petukhova MZ, Kessler RC: Telephone screening, outreach, and care management for depressed workers and impact on clinical and work productivity outcomes: a randomized controlled trial. JAMA 2007, 298:1401-11.

13. Lo Sasso AT, Rost K, Beck A: Modeling the impact of enhanced depression treatment on workplace functioning and costs: a cost-benefit approach. Med Care 2006, 14:352-358

14. Mintz J, Mintz LI, Arruda MJ, Hwang SS: Treatments of depression and the functional capacity to work. Arch Gen Psychiatry 1992, 49:761-768.

15. National Center for Health Statistics: Employer-Sponsored Health Insurance: State and National Estimates. Hyattsville, MD 1997.

16. Schoenbaum M, Kelleher K, Lave JR, Green S, Keyser D, Pincus H: Exploratory evidence on the market for effective depression care in Pittsburgh. Psychiatr Serv 2004, 55:392-395.

17. Wells KB, Miranda J, Bauer MS, Bruce ML, Durham M, Escobar J, Ford D, Gonzalez J, Hoagwood K, Horwitz SM, Lawson W, Lewis L, McGuire T, Pincus $H$, Scheffler $R$, Smith WA, Unützer J: Overcoming barriers to reducing the burden of affective disorders. Biol Psychiatry 2002, 52:655-675.

18. Pincus HA, Pechura CM, Elinson L, Pettit AR: Depression in primary care: linking clinical and systems strategies. Gen Hosp Psychiatry 2001 23:311-318.

19. Frank $R G$, Huskamp $H A$, Pincus $H A$ : Aligning incentives in the treatment of depression in primary care with evidence-based practice. Psychiatr Serv 2003, 54:682-687.

20. Goldberg RJ, Steury S: Depression in the workplace: costs and barriers to treatment. Psychiatr Serv 2001, 52:1639-1643.

21. Croghan TW: The controversy of increased spending for antidepressants. Health Aff (Millwood) 2001, 20:129-135.

22. Berndt ER, Bir A, Busch SH, Frank RG, Normand SL: The medical treatment of depression, 1991-1996: productive inefficiency, expected outcome variations, and price indexes. J Health Econ 2002, 21:373-396.

23. Olfson M, Marcus SC, Druss B, Elinson L, Tanielian T, Pincus HA: National trends in the outpatient treatment of depression. JAMA 2002, 287:203-209.

24. Peele PB, Lave JR, Black JT, Evans JH: Employer-sponsored health insurance: are employers good agents for their employees? Milbank $Q$ 2000, 78:5-21.

25. Depression Care Management. [http://www.caremanagementfordepression. org].

26. Horgan CM, Merrick EL, Stewart MT, Stewart MT, Scholle SH, Shih S: Improving Medication Management of Depression in Health Plans. Psychiatr Serv 2008, 59:72-77.

27. Rost K, Smith J, Fortney J: Large employers' selection criteria in purchasing behavioral health benefits. J Behav Health Serv Res 2000, 27:334-338. 
28. Rosenthal MB, Landon BE, Normand SL, Frank RG, Ahmad TS, Epstein AM: Employers' use of value-based purchasing strategies. JAMA 2007, 298:2281-2288.

29. Maio V, Hartmann CW, Goldfarb NI, Roumm AR, Nash DB: Are employers pursuing value-based purchasing? Benefits Q 2005, 21:20-29.

30. Marquis MS, Long SH: of selected employer health insurance purchasing strategies in 1997. Health Aff(Millwood) 2001, 20:220-230.

31. Hibbard JH, Jewett JJ, Legnini MW, Tusler M: Choosing a health plan: do large employers use the data?. Health Aff(Millwood) 1997, 16:172-180.

32. Influencing Employee Benefit Purchasing-Supporting Materials. [http:// rost.med.fsu.edu].

doi:10.1186/1748-5908-5-22

Cite this article as: Rost and Marshall: Marketing depression care

management to employers: design of a randomized controlled trial.

Implementation Science 2010 5:22.

\section{Submit your next manuscript to BioMed Central} and take full advantage of:

- Convenient online submission

- Thorough peer review

- No space constraints or color figure charges

- Immediate publication on acceptance

- Inclusion in PubMed, CAS, Scopus and Google Scholar

- Research which is freely available for redistribution

Submit your manuscript at www.biomedcentral.com/submit 